\title{
Production of antioxidant xylooligosaccharides from lignocellulosic materials using Bacillus amyloliquifaciens NRRL B-14393 xylanase
}

\author{
Mona M. Rashad ${ }^{1 *}$, Abeer E. Mahmoud ${ }^{1}$, Mohamed U. Nooman ${ }^{1}$, Hadeer A. Mahmoud ${ }^{1}$, Alaa El-Din M.M. El-Torky ${ }^{2}$, \\ Akaber T. Keshta ${ }^{2}$ \\ ${ }^{1}$ Biochemistry Department, Division of Genetic Engineering and Biotechnology, National Research Centre, Cairo, Egypt. ${ }^{2}$ Chemistry Department, Faculty \\ of Science, Zagazig University, Zagazig, Egypt.
}

\begin{tabular}{|c|c|}
\hline ARTICLE INFO & ABSTRACT \\
\hline Article history: & \multirow{11}{*}{$\begin{array}{l}\text { The present study aimed to evaluate the enzymatic production of XOS, antioxidant activities together with total } \\
\text { phenolic contents from different lignocellulosic materials and birchwoodxylan using both crude and pure forms } \\
\text { of Bacillus amyloliquifaciens NRRL B-14393 xylanase respectively. The mode of action of the pure xylanase } \\
\text { was studied by HPLC and the end products analysis of birchwoodxylan revealed that xylose, xylobiose and } \\
\text { xylotriose were the only end products. The resulted XOS mixture exhibited potent antioxidant activity of } 87.36 \\
\% \text { and high total phenolic content of } 182.88 \mathrm{mg} \text { GAE/ liter of extract. XOS were obtained from different alkali } \\
\text { pretreated agricultural residues by the crude xylanase action with a yield in a range from } 54.4 \% \\
\text { to } 85.5 \% \text {. Maximum scavenging abilities and total phenolic contents of XOS mixtures of all the tested materials } \\
\text { were determined. XOS mixtures of orange and mango peels revealed relatively higher antioxidant activities } \\
(96 \% \text { and } 76.84 \% \text {, respectively) and total phenolic acid contents (156.32 and } 133.74 \mathrm{mg} \text { GAE/ liter of extract, } \\
\text { respectively) compared to the other XOS mixtures. In conclusion, Bacillus amyloliquifaciens NRRL B-14393 } \\
\text { xylanase could be a promising source for production of XOS with high phenolic contents and antioxidant } \\
\text { activities. }\end{array}$} \\
\hline $3 / 03 / 2016$ & \\
\hline $\operatorname{Re}$ & \\
\hline $\mathrm{Ac}$ & \\
\hline Availa & \\
\hline Key $w$ & \\
\hline Xylanase; & \\
\hline xylooligosaccharides; & \\
\hline antioxidant; lignocellulosic & \\
\hline materials; Bacillus & \\
\hline $\begin{array}{l}\text { amyloliquifaciens NRRL B- } \\
14393 \text {. }\end{array}$ & \\
\hline
\end{tabular}

\section{INTRODUCTION}

Currently, research on converting the agricultural byproducts into value added products is actively undertaken to produce different economically important biomolecules; one of them isxylooligosaccharides (XOS). These oligomeric carbohydrates, a class of non-digestible food ingredients having a degree of polymerization (DP) of 2-6, is produced during the hydrolysis of xylan, the most abundant component of the plant hemicelluloses (Brienzo et al., 2010). XOS are indigestible by gastric or pancreatic enzymes, but able to be utilized by selected group of beneficial gut microflora associated with several health physiological benefits including reduction of blood cholesterol,

\footnotetext{
* Corresponding Author

Mona M. Rashad, Biochemistry Department, Division of Genetic Engineering and Biotechnology, National Research Centre, Cairo, Egypt.Email:monarashad122@hotmail.com
}

maintenance of gastrointestinal health, reducing the risk of colon cancer, beneficial to type 2 diabetes mellitus, increase of mineral absorption (Ando et al., 2004; Swennen et al., 2006; Mussatto and Mancilha, 2007; Sheu et al., 2007). Additionally, XOS are valuable food sweetener of prebiotic, non-carcinogenic and antifreezing activities so it could be incorporated as additive in beverages and fermented dairy products (Crittenden and Playne, 1996; Kabel et al., 2002; Yang et al., 2005). XOS are mainly produced by acid hydrolysis of hemicellulosic materials, which is considered environment unfriendly (Vazquez et al., 2000). The other approaches involve trans-glycosylation reactions viaglycosyltranferases and glycosynthase $\beta$-xylosidases. These processes are expensive due to purification steps involved and need pure monosaccharides as raw materials. Due to high cost of production, its use in functional foods is uneconomical (Mussatto and Mancilha, 2007). A more developed process for obtaining purified XOS are necessary. 
The enzymatic production of XOS is considered a promising alternative strategy compared to chemical processes due to the production of easily recovered, highly pure XOS with a fewer undesirable byproducts (Akpinar et al., 2007; Zhao et al., 2012). Xylanases (E.C. 3.2.1.8) are hemicellulases responsible for the degradation of $\beta-1,4 x y l a n$ in a random fashion, yielding a series of linear and branched oligosaccharide fragments (Bhat and Hazlewood, 2001). It has been shown in our previous papers (Rashad et al, $2015 \mathrm{a}, \mathrm{b})$ that the crude and pure enzymes from Bacillus amyloliquifaciens NRRL B-14393 are endowed with a number of promising properties that enhanced their industrial potential. Therefore, this study was aimed to produce XOS from different lignocellulosic materials and birchwoodxylan. Furthermore, the antioxidant activities and total phenolic contents of the produced XOS were evaluated.

\section{MATERIALS AND METHODS}

\section{Plant material}

Water hyacinth plant (WH) was collected in winter season from Mansoureya canal, Giza, Egypt. Its roots were cut off and the green parts (stem and leaves) were thoroughly washed with tap water, sliced, crushed in a mixer to small pieces $0.5-1 \mathrm{~cm}$ and store at $4^{\circ} \mathrm{C}$ till use. Then this substrate was used as a sole carbon source for the production of the xylanase.

\section{The agroindustrial wastes}

Mango peels, orange peels and sugarcane bagasse were obtained from juice processing shops in the local market. Corn cobs, wheat bran, rice straw and saw dust were purchased from the local market. All these materials were dried in an oven at $60^{\circ} \mathrm{C}$ till constant weight for each one was achieved (A.O.A.C. 1995), then mechanically ground (except wheat bran) in an electric miller and sieved to a particle size ranged from 10 to 200 mesh.

\section{Experimental organism}

Bacillus amyloliquifaciens NRRL B-14393was obtained from Agricultural Research Service, Peoria, Illinois, USA. The strain was maintained on nutrient agar slant containing ( $3 \mathrm{~g} / \mathrm{l}$ beef extract, $5 \mathrm{~g} / \mathrm{l}$ peptone, $8 \mathrm{~g} / \mathrm{l}$ sodium chloride and $15 \mathrm{~g} / \mathrm{l}$ agar), then stored at $4{ }^{\circ} \mathrm{C}$ and sub-cultured monthly. Inoculum was developed by transferring a loopful of stock culture into a sterile nutrient medium and incubated at $37^{\circ} \mathrm{C}$ on a shaker at $200 \mathrm{rpm}$ for $24 \mathrm{~h}$.

\section{Production and purification of xylanase}

Ten gram of fresh water hyacinth plant (leaves and stems) supplemented with $0.5 \%$ (w/w) sucrose ( initial pH 6; 95\% moisture level)was placed in 100-ml Erlenmeyer flasks and autoclaved at $121{ }^{\circ} \mathrm{C}$ for $15 \mathrm{~min}$, cooled and then inoculated with $7 \%$ of B. amyloliquifaciens inoculum. The inoculated medium was then incubated statically for $24 \mathrm{~h}$. at $35^{\circ} \mathrm{C}$ as previously prepared (Rashad et al., 2015a).

The enzyme was extracted from the fermented matter with $10-$ fold $(\mathrm{v} / \mathrm{w})$ distilled water by shaking $(200 \mathrm{rpm})$ at $30^{\circ} \mathrm{C}$ for
60 min (Yang et al., 2006). The resultant slurry was filtered through a wet muslin cloth and centrifuged at 10,000xg for $15 \mathrm{~min}$. Finally, the extracts were collected and considered as a source of crude enzyme.

The crude enzyme purification was carried out on DEAE-Sepharose ion-exchange column followed by gel filtration chromatography on Sephadex G-100 (Rashad et al., 2015b) and used in this study.

\section{Xylanase assay}

Xylanase activity was measured by incubating $1.0 \%$ $(\mathrm{w} / \mathrm{v})$ birch wood xylan in $0.05 \mathrm{M}$ acetate buffer ( $\mathrm{pH} 5.5)$ and an appreciable amount of diluted enzyme extract $(0.1 \mathrm{ml})$ in a total volume of $0.3 \mathrm{ml}$ at $50^{\circ} \mathrm{C}$ for $60 \mathrm{~min}$ (Rashad et al., 2002). The release of reducing sugar was measured as xylose by SomogyiNelson method (Nelson, 1944; Somogyi, 1952) using xylose as a standard. One unit (U) of xylanase is defined as the amount of enzyme that releases $1 \mu \mathrm{mol}$ xylose/min under the assay conditions. The specific activity is expressed as units per $\mathrm{mg}$ of protein.

\section{Protein determination}

For specific activity determination, protein was measured by Lowry et al.(1951) method using a bovine serum albumin as a standard.

\section{Mode of action and end product analysis}

Purified xylanase $(0.25 \mathrm{mg} / \mathrm{ml})$ was incubated with substrate $(10 \mathrm{mg} / \mathrm{ml})$ in $5 \mathrm{mMtris}-\mathrm{HCl}$ buffer $(\mathrm{pH} 9.5)$ at $50{ }^{\circ} \mathrm{C}$ for various time intervals $(1 / 2 \mathrm{~h}, 2.5 \mathrm{~h}, 6 \mathrm{~h}$ and $24 \mathrm{~h})$, then aliquots were withdrawn, boiled for $5 \mathrm{~min}$ and filtered through a $0.45 \mu \mathrm{m}$ membrane. The hydrolyzed reaction products were analyzed by HPLC, Shimadzu Class-VPV 5.03 (Kyoto, Japan) equipped with refractive index RID-10A Shimadzu detector, LC-16ADVP binary pump, DCou-14 A degasser and Shodex PL Hi-PlexPb column (Sc 1011 No. H706081), Guard column Sc-LcShodex, and heater set at $65^{\circ} \mathrm{C}$

Twenty-microliter samples from both reaction mixtures and standards (xylose, xylobiose, xylotriose and arabinose at concentration of $0.2 \mathrm{mg} / 20 \mu \mathrm{l}$ except for xylose which was at $4 \mathrm{mg} / \mu \mathrm{l}$ ) were injected and eluted on an amino-bonded column with acetonitrile: water (80:20) as a mobile phase at a flow rate of $1 \mathrm{ml} / \mathrm{min}$ (A.O.A.C. 1997)

\section{Xylooligosaccharides production from birchwoodxylan by pure B. amyloliquefaciens xylanase}

Purified xylanase $(0.25 \mathrm{mg} / \mathrm{ml})$ was incubated with birch wood xylan $(10 \mathrm{mg} / \mathrm{ml})$ at $5 \mathrm{~m}$ Mtris- $\mathrm{HCl}$ buffer $(\mathrm{pH} 9.5)$. Reaction mixture were incubated at $50{ }^{\circ} \mathrm{C}$ for $150 \mathrm{~min}$. The hydrolysis was repeated several times to obtain sufficient XOScontaining liquor then concentrated by lyophilization. The concentrated XOS were dissolved in distilled water to obtain concentrations of (0.5-20) mg ml${ }^{-1}$ for further studies. 


\section{Alkali treatment of different wastes}

Alkali treatment was conducted by suspending $25 \mathrm{~g}$ of different substrates (corn cobs, wheat bran, sugarcane bagasse, rice straw, water hyacinth, mango peels, saw dust and orange peels) in $500 \mathrm{ml}$ of $0.5 \%$ sodium hydroxide solution $(0.1 \mathrm{~g} \mathrm{NaOH} / \mathrm{g}$ substrate) in a 1 liter conical flask and boiling for $1 \mathrm{~h}$ in a water bath (Choudhury et al., 1980; Rashad et al., 2015a).

\section{Xylooligosaccharides (XOS) production from agricultural lignocellulosic wastes by crude $B$. amyloliquefaciens xylanase}

Pretreated corn cobs, wheat bran, sugarcane bagasse, rice straw, water hyacinth, mango peels, saw dust and orange peels (10 mg dry wt.) were dispersed in acetate buffer ( $\mathrm{pH} 5.5,0.05 \mathrm{M}$ ), treated with the crude xylanase in a final volume of $10 \mathrm{ml}$ and incubated for $72 \mathrm{~h}$ at $50{ }^{\circ} \mathrm{C}$ followed by centrifugation $(3,000 \times \mathrm{g})$ (Rashad et al., 2013a).

The hydrolysis was repeated several times to obtain sufficient XOS-containing liquor. To the supernatant, three volumes of ethanol were added to precipitate the unhydrolyzed hemicelluloses (Bian et al., 2013). Ethanol was removed from the filtrate by rotary evaporation under reduced pressure at $45^{\circ} \mathrm{C}$, and the solid fraction was freeze-dried. The concentrated XOS were used for the further studies.

\section{DPPH radical-scavenging assay}

Antioxidant activity of XOS was measured by the effect of scavenging 2,2-diphenyl-1-picrylhydrazyl radicals according to the modified methods of Mensor et al.(2001) and Veenashri and Muralikrishna (2011). One $\mathrm{ml}$ of $0.1 \mathrm{mM}$ DPPH in ethanol was added to $1 \mathrm{ml}$ of the XOS solution at different concentrations. The mixture was shaken vigorously and kept for $30 \mathrm{~min}$ in the dark at room temperature $\left(30 \pm 1^{\circ} \mathrm{C}\right)$. The absorbance was measured at $517 \mathrm{~nm}$. The control was carried out with water instead of the sample solution (1:1dilution of DPPH), while ethanol was used as the blank. The capability of the sample to scavenge the DPPH radicals was calculated using the following equation:

Scavenging activity $(\%)=[1$ - (absorbance sample / absorbance control)] x $100 \%$

\section{Total phenolics assay}

Total phenolics were estimated as gallic acid equivalents essentially according to that described by Quettier-Deleu et al.(2000)with minor modification. An aliquot of $0.5 \mathrm{ml}$ of the XOS solution at different concentrations was added to $7.0 \mathrm{ml}$ deionized water and $0.5 \mathrm{ml}$ Folin-Ciocalteu phenol reagent. After $3 \mathrm{~min}, 2.0 \mathrm{ml}$ of $20 \% \mathrm{Na}_{2} \mathrm{CO}_{3}$ were added and heated in a boiling water bath for $1 \mathrm{~min}$ comparatively to gallic acid standard. Absorbance was measured at $750 \mathrm{~nm}$ after cooling in darkness and the results expressed in $\mathrm{mg}$ of gallic acid equivalent per liter of extract.

\section{Statistical analysis}

The results are reported as Mean \pm Standard error (S.E.) for at least four times experiments.

\section{RESULTS AND DISCUSSION}

Xylooligosaccharides (XOS) production from birchwoodxylan by purified $B$. amyloliquefaciens xylanase

Xylanases have attracted considerable attention because of their industrial application in the production of XOS (Vazquez et al., 2000; Moure et al., 2006). The mode of action of only a few homogeneously purified endoxylanases of microbial origin has been studied, either by research on kinetics, determining $K_{m}$ and $\mathrm{V}_{\max }$ values (Hiromi, 1970) or by end product analysis (Thoma et al., 1970). Of the two techniques, end product analysis is more suitable for endotype hydrolyzing enzymes, while the kinetic method is particularly useful for exo-type hydrolases (Suganuma et al., 1978). The hydrolysis products of birchwoodxylan by purified B. amyloliquefaciens xylanase were analyzed by HPLC. Figure (1a-d) illustrated the HPLC pattern of standard sugars (xylose, xylobiose, xylotriose and arabinose, respectively).
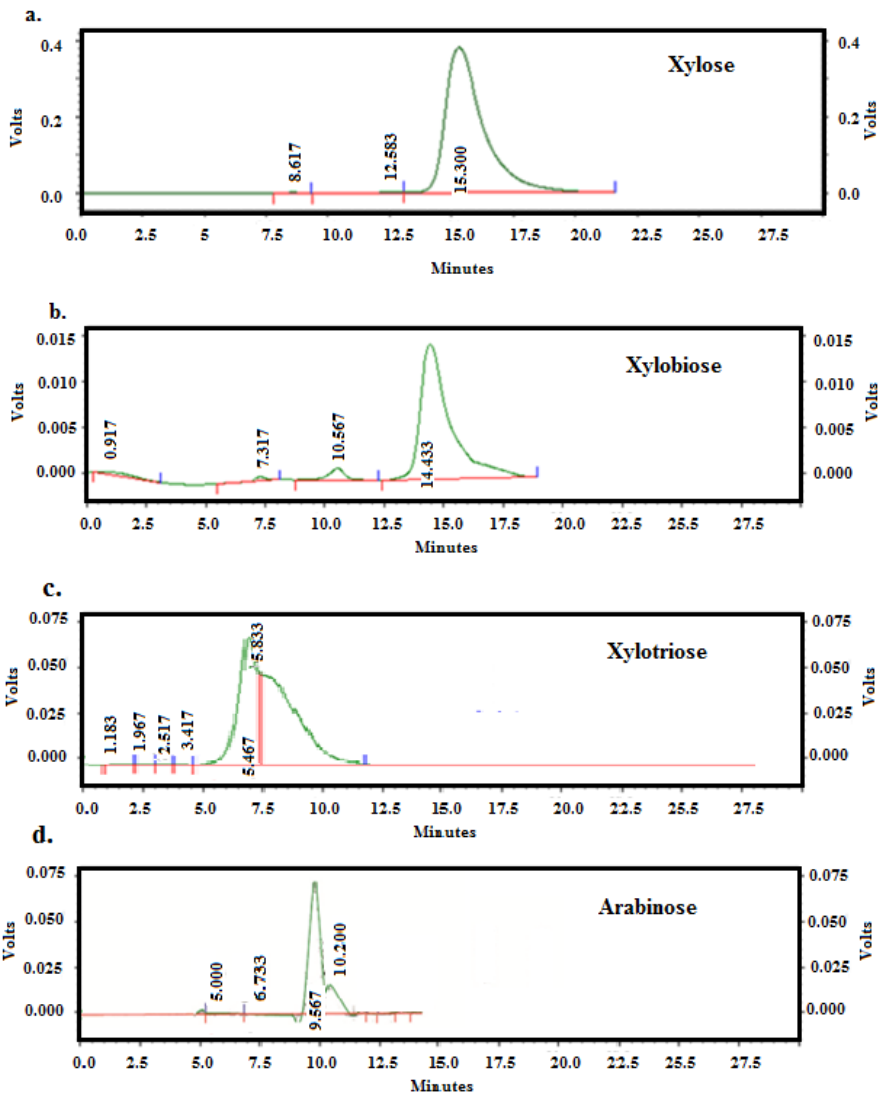

Fig. 1: Typical HPLC chromatograms of standards (a- xylose, b-xylobiose, cxylotriose and d-arabinose standards)

The use of pure B. amyloliquefaciens xylanase allowed for the production of value added compounds, such as XOS from birchwoodxylan. In the reaction of xylan with pure $B$. amyloliquefaciens xylanase (Rashad et al., 2015b), the end products of xylan hydrolysis in the early stage are xylose, xylobiose (Fig.2a).After $150 \mathrm{~min}$, xylotriose was formed reaching to $41.94 \%$, whereas xylose and xylobiose represented $13.22 \%$ and $44.84 \%$, respectively (Fig. 2 b). With time course of hydrolysis, the amount of xylose and xylobiose increased slowly reaching to 
$15.25 \%$ and $45.35 \%$,respectively. While the amount of xylotriose decreased to $39.40 \%$ of the products produced in $6 \mathrm{~h}$ (Fig. $2 \mathrm{c})$. When the reaction time was further extended to $24 \mathrm{~h}$, the XOS (X $-\mathrm{X} 3$ ) content increased with xylobiose as the major end product $(45.66 \%)$, xylose $(20.67 \%)$ and xylotriose $(33.67 \%)$ suggesting the applicability of the enzyme in bioconversion of birchwoodxylan into XOS (Fig.2 d).
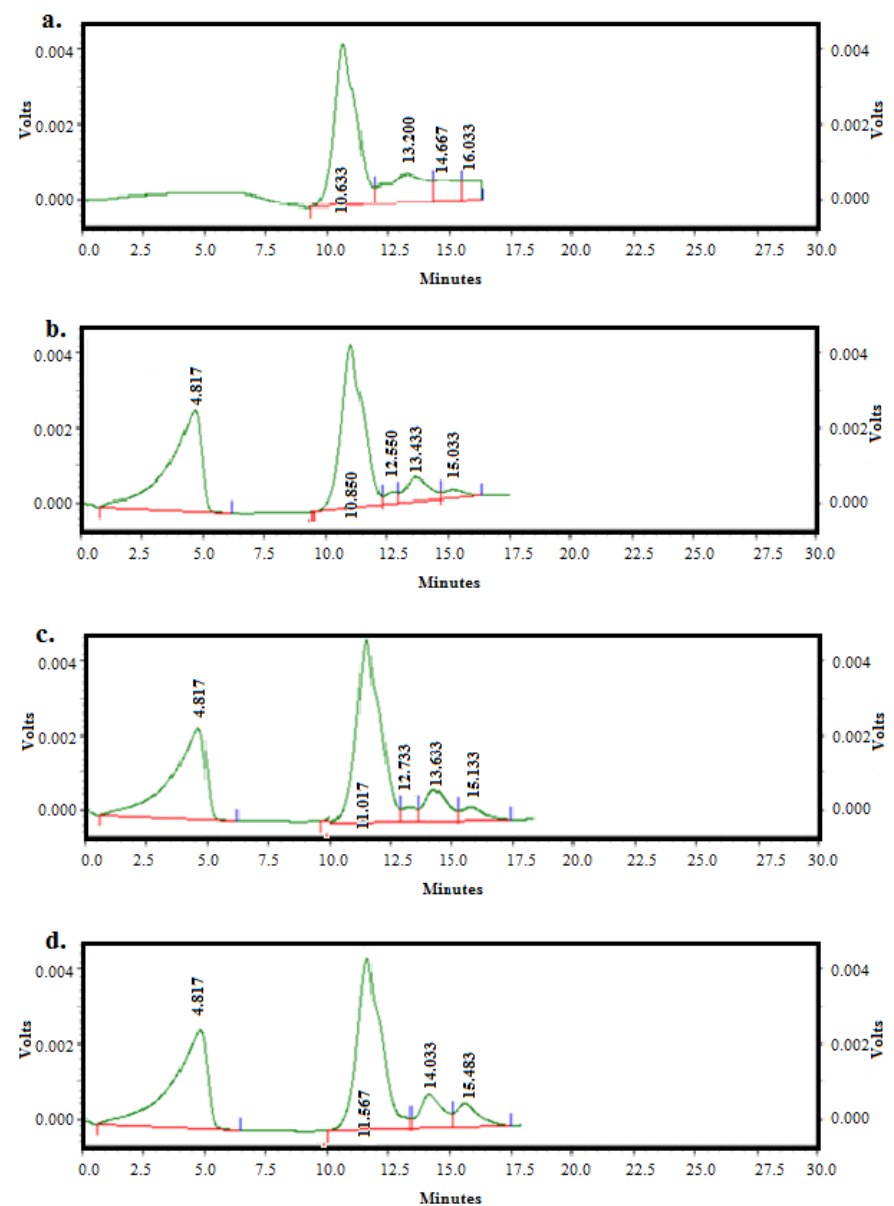

Fig. 2:Typical HPLC chromatograms of birchwoodxylan hydrolysis produced by $B$. amyloliquefaciens pure xylanase after various time interval ( a-30 min, b-150 min, c- 6 h, d- 24 h).

These results were in accordance with xylanases isolated from Pleurotus ostreatus (Fathy et al., 2003), Clostridium thermocellum (Mandelli et al., 2014) and Streptomyces sp. CS624 (Mander et al., 2014). In the case of Bacillus sp. strain SPS-0 xylanase, the major products of hydrolysis of birch wood xylan were xylose and xylobiose (Bataillon et al., 2000). Rashad et al.(2015b) reported that the B. amyloliquefaciens NRRL B-14393 pure xylanase molecular mass $(29 \mathrm{kDa})$, substrate versatility, thermal stability in addition the mode of action in this study suggests that the enzyme is an endoxylanase of the glycoside hydrolase family 11 . Thus, the B. amyloliquefaciens NRRL B14393 xylanase could be used to produce XOS, which can be used as functional food additives for the selective growth of humanbeneficial intestinal microflora (Laskowski et al., 1993). These characteristic is common to Penicillium griseofulvum and
Penicillium funiculosum GH11 xylanases that yield xylobiose and xylotriose as the main end reaction products (Tison et al., 2009; Driss et al., 2011).However, Kumar and Satyanarayana (2011) reported that $B$. haloduransTSEV1 xylanase hydrolyzed xylan to xylobiose-xyloheptaose (X2-X7). Also, the results in Figs.2A-D showed the absence of arabinose as hydrolysis end products. This enzyme cannot act on L-arabinosyl initiated points at $\beta-(1 \rightarrow 4)$ linkages and produce xylotriose, xylobiose and xylose as the major end products. This endo-xylanase enzyme can break down XOS as small as xylobiose (Bastawde, 1992; Fathy et al., 2003). While, The products of hydrolysis of the birch wood xylan by Gracilibacillus sp. TSCPVG were arabinose, xylose-xylotetraose (X-X4) (Giridhar and Chandra, 2010).Moreover, Toshio et al.(1990), reported that because of its less calorific value, xylobiose, a derivative of XOS was used as sweetener.

\section{Antioxidant activity and total phenolic content of the xylooligosaccharides (XOS) produced from birchwoodxylan by pure B. amyloliquefaciens xylanase}

Scavenging ability and total phenolic content of XOS obtained after $150 \mathrm{~min}$ enzymatic hydrolysis at various concentrations are shown in Figs. 3 and 4. The DPPH assay showed that the antioxidant activity of XOS exhibited a dosedependent behavior. The scavenging effect of XOS was gradually increased and reached $87.36 \%$ at a concentration of $5 \mathrm{mg} / \mathrm{ml}$, after which it gradually decreased to $81.16 \%$ at $15 \mathrm{mg} / \mathrm{ml}$ concentration and upto $20 \mathrm{mg} / \mathrm{ml}$ it was stabilized.

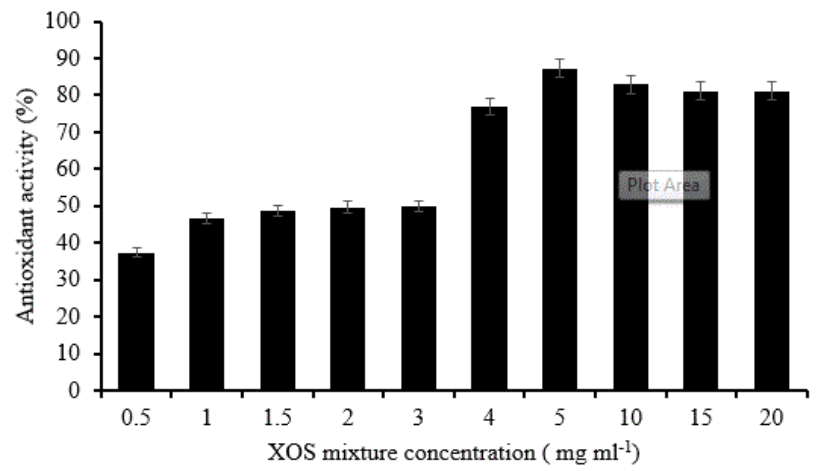

Fig. 3: Antioxidant activity against DPPH of XOS obtained by enzymatic hydrolysis for $150 \mathrm{~min}$.

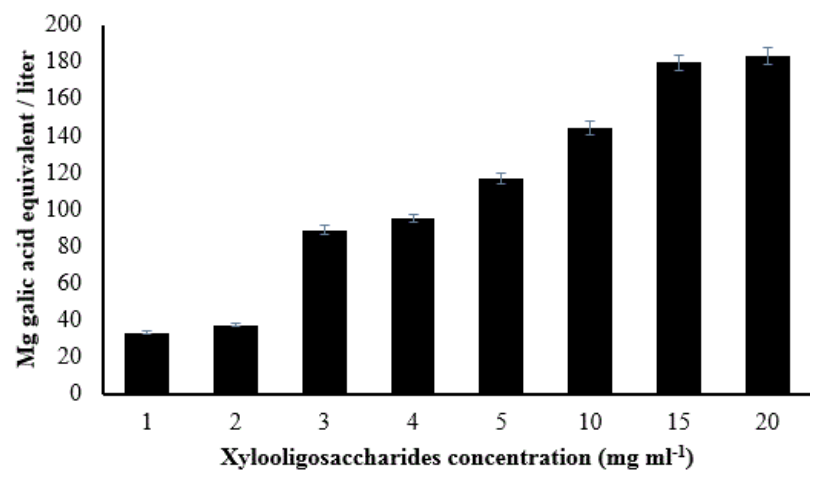

Fig. 4: Determination of total phenolic content of XOS produced from birchwoodxylan by pure $B$. amyloliquefaciens xylanase. 
Even though the concentration of the total phenolic content of XOS mixture at $5 \mathrm{mg} / \mathrm{ml}$ was of $116.86 \mathrm{mg} \mathrm{GAE} /$ liter of extract which is lower than the values (144.17-182.88 mg GAE/ liter of extract) attained at higher concentrations $(10-20 \mathrm{mg} / \mathrm{ml}$ concentration), its antioxidant activity was comparatively highest $(87.36 \%)$. From this it can be assumed that the type of phenolic compounds are important more than the total phenolics for the effective antioxidant activity (Reddy and Krishnan, 2010)

\section{Production of Xylooligosaccharides (XOS) by enzymatic degradation of agricultural lignocellulosic wastes}

Considering the demand for XOS in pharmaceutical, food and other industries finding renewable, cheap xylan sources, instead of the hardwood xylan, are necessary for the preparation of XOS. Utilization of agricultural biomass as raw material provides economic and ecological benefits because it reduces the amount of waste and makes possible to recover high value added compounds. XOS were obtained from the pretreated wheat bran, orange peels, rice straw, mango peels, sugarcane bagasse, corn cobs, saw dust and WH plant by crude xylanase treatment for $72 \mathrm{~h}$ at $50{ }^{\circ} \mathrm{C}$ (Fig.5).

The profile of the XOS yield was different for each substrate used, where the highest amount was obtained from enzymatic hydrolysis of wheat bran $(85.50 \%)$ followed by orange peels $(85 \%)$, rice straw $(84.6 \%)$, mango peels $(84 \%)$, sugarcane bagasse $(69 \%)$, corn cobs $(58 \%)$, saw dust $(56 \%)$ and WH plant $(54 \%)$.

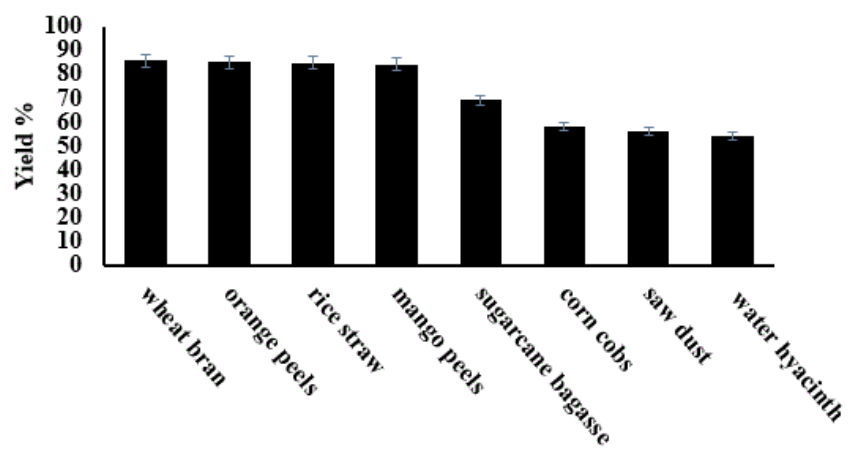

Substrate

Fig. 5:Xylooligosaccharides (XOS) production from pretreated agricultural lignocellulosic wastes by crude B. amyloliquefaciens xylanase.

These results indicate that the greatest enzymatic conversion yield correlated to the lowest structural substrate complexity (Mandelli et al., 2014). Xylanase, an endolytic enzyme cleaves the backbone of xylan randomly at the places where there are two or more contiguous unsubstituted xylose residues that serve as easy access point for cleavage. The resulting product vary in degree of polymerization ranging from xylose, xylobiose, xylotriose, to higher XOS (Yuan et al., 2005).

From the results we can further generalize that wheat bran is rich in sugars compared to the other substrates resulting in high amount of XOS. Lower values of wheat bran XOS were produced by xylanases of $P$. pastoris, $B$. subtilis and $T$. lanuginosus (31, 44.25 and 40\%) (Jun et al., 2009; Reddy and Krishnan, 2010; Veenashri and Muralikrishna, 2011), respectively.

Antioxidant activities and total phenolic contents of the xylooligosaccharides (XOS) produced from agricultural lignocellulosic wastes by crude $B$. amyloliquefaciens xylanase

The in vitro antioxidant activity and total phenolic acid contents of the XOS mixtures obtained by enzymatic hydrolysis of all the residues used in this study are shown in Figs.6 and 7. The sensitivity of the scavenging abilities is determined by the strong absorption of DPPH. The best results for antioxidant activity and phenolics production content were observed for orange peels XOS mixtures (96\% and $156.32 \mathrm{mg} \mathrm{GAE} /$ liter of extract, respectively) followed by mango peels XOS mixtures $(76.84 \%$ and $133,74 \mathrm{mg}$ GAE/ liter of extract ,respectively) at $1000 \mu \mathrm{g} / \mathrm{ml}$ concentration. The antioxidant activities and total phenolic contents exhibited by the other XOS mixtures ranged between (10-20\%) and (11.59$49.72 \mathrm{mg}$ GAE/ liter of extract) at various concentrations. Although, the percentage of XOS conversion is more in the case of wheat bran ,but the antioxidant activity and total phenolics were less because lignin phenolics are not contributing to the yield (Reddy and Krishnan, 2010).

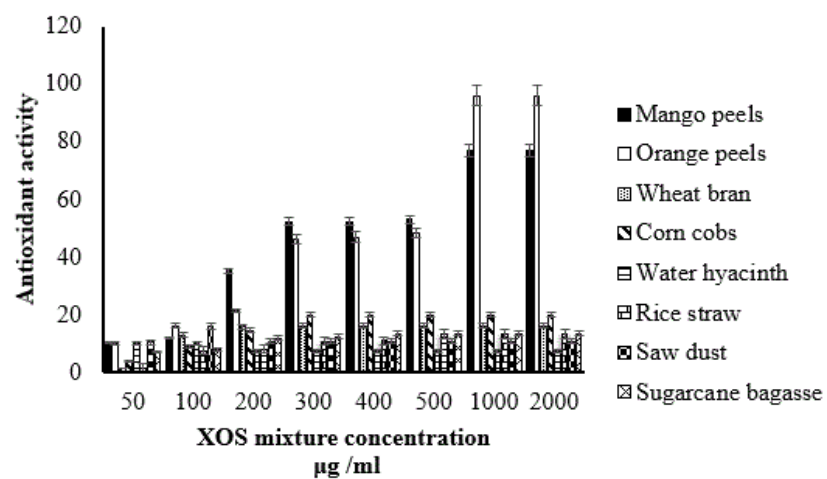

Fig. 6: Antioxidant activity against DPPH of XOS obtained by enzymatic hydrolysis of agricultural lignocellulosic wastes for $72 \mathrm{~h}$.

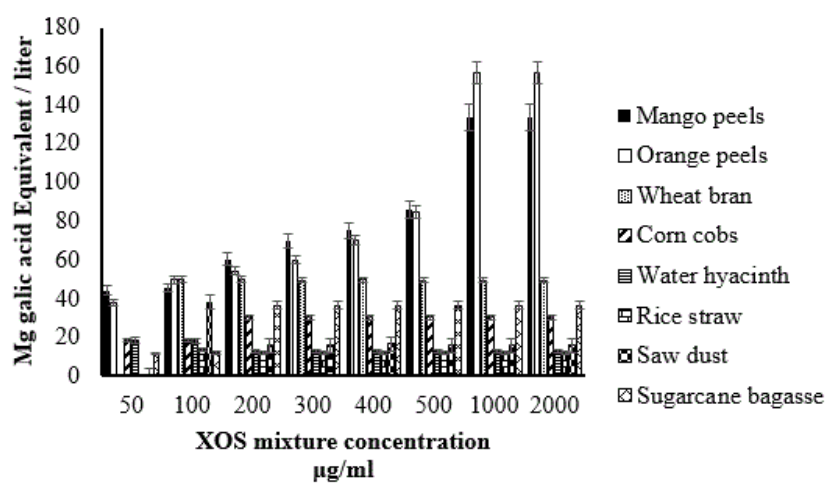

Fig. 7: Estimation of total phenolic content of the XOS produced from agricultural lignocellulosic wastes by crude $B$. amyloliquefaciensxylanase.

The XOS exhibited concentration dependent antioxidant activity. A similar behavior has been reported for other XOS, from cereal, millet brans and sugarcane bagasse (Veenashri and Muralikrishna, 2011; Bian et al., 2013;Rivas et al., 2013; Lin et 
al.,2014).The total phenolic acid content and in addition its nature plays a significant role on the overall anti-oxidant capacity of the XOS mixtures (Veenashri and Muralikrishna, 2011).

The relatively higher antioxidant activities of XOS mixtures derived from orange peels and mango peels compared to other XOS mixtures could be explained by the presence of higher amount of total phenolic acid contents. Veenashri and Muralikrishna (2011) reported that the activity exhibited by the XOS mixture from ragi has been justified by the contents of ferulic and syringic acids.

The antioxidant activity exhibited by XOS from orange peels was higher than that of wheat bran, rice, maize, sugarcane bagasse, rice husk and bamboo bagasse XOS mixtures (Reddy and Krishnan, 2010; Veenashri and Muralikrishna, 2011; Bian et al., 2013). The above results indicated that XOS from orange peels and mango peels can be exploited in preparing nutritional health foods.

\section{CONCLUSIONS}

Our findings demonstrated the biotechnological potential for use of both crude and pure B. amyloliquefaciens xylanases in the hydrolysis of agro-industrial residue by-products and birch wood xylan respectively. The bi-functionality of $B$. amyloliquefaciens xylanase allowed for simultaneous extraction of XOS and antioxidant compounds from plant biomass.

\section{ACKNOWLEDGEMENTS}

This work was supported by the National Research Centre, Egypt (Project no.10130105).

\section{REFERENCES}

Akpinar O, Ozlem AK, Kavas A, Bakir U, Yilmaz L. Enzymatic production of xylooligosaccharides from cotton stalks. J Agric Food Chem, 2007; 55: 5544-5551.

Ando H, Ohba H, Sakaki T, Takamine K, Kamino Y, Moriwaki S. Hot compressed water decomposed products from bamboo manifest a selective cytotoxicity against acute lymphoblastic leukemia cells. Toxicol. In Vitro, 2004; 18: 765-771.

AOAC.:Official methods of analysis of the Association of Official Analytical Chemists, 16th ed., Washington, D.C., USA, 1995.

AOAC.:Official methods of analysis of the Association of Official Analytical Chemists, 17th ed., Washington, D.C., USA, 1997.

Bastawde K. Xylan structure, microbial xylanases, and their mode of action. World J MicrobiolBiotechnol, 1992; 8: 353-368.

Bataillon M, Cardinali A.-PN, Castillon N, Duchiron F. Purification and characterization of a moderately thermostable xylanase from Bacillus sp. strain SPS-0, Enzyme. MicrobTechnol, 2000; 26:187-92.

Bhat MK, Hazlewood GP. 2001. Enzymes in Farm Animal Nutrition.In: BedfordMR, and Partridge CC, ed.Wallingford UK: CAB International 11-60.

Bian J, Peng F, Peng X.-P, Peng P, Xu F, Sun R.-C. Structural features and antioxidant activity of xylooligosaccharides enzymatically produced from sugarcane bagasse. BioresourTechnol, 2013; 127: 236-241.

Brienzo M, Carvalho W, Milagres AMF. Xylooligosaccharides production from alkali pretreated sugarcane bagasse using xylanase from Thermoascusaurantiacus. Appl Biochem Biotechnol, 2010;162:119-1205.

Choudhury N, Gray P, Dunn N. Reducing sugar accumulation from alkali pretreated sugar cane bagasse using Cellulomonas. Eur J ApplMicrobiolBiotechnol, 1980; 11: 50-54.
Crittenden R, Playne M. Production, properties and application of food grade oligosaccharides. Trends Food SciTechnol, 1996; 7: 353-61.

Driss D, Bhiri F, Elleuch L, Bouly N, Stals I, Miled N, Blibech M, Ghorbel R, Chaabouni SE. Purification and properties of an extracellular acidophilic endo-1, 4- $\beta$-xylanase, naturally deleted in the "thumb", from Penicilliumoccitanis Pol6. Process Biochem, 2011; 46: 1299-1306.

Fathy SA, Rashad MM, Abdou HM, Mahmoud AE, Jwanny EW. Purification and characterization of $P$. ostreatus xylanase. Model Meas Control, 2003; 64: 1-18.

Giridhar PV, Chandra T. Production of novel halo-alkalithermo-stable xylanase by a newly isolated moderately halophilic and alkali-tolerant Gracilibacillus sp. TSCPVG. Process Biochem, 2010; 45:1730-1737.

Hiromi K. Interpretation of dependency of rate parameters on the degree of polymerization of substrate in enzyme-catalyzed reactions. Evaluation of subsite affinities of exo-enzyme. BiochemBiophys Res Commun, 1970; 40: 1-6.

Jun H, Bing Y, Keying Z, Daiwen C. Functional characterization of a recombinant thermostable xylanase from Pichiapastoris: A hybrid enzyme being suitable for xylooligosaccharides production. BiochemEng J, 2009; 48: 87-92.

Kabel MA, Schols HA, Voragen AGJ. Complex xylooligosaccharides identified from hydrothermally treated Eucalyptus wood and brewery' s spent grain. CarbohydrPolym, 2002; 50: 191-200.

Kumar V, Satyanarayana T. Applicability of thermo-alkalistable and cellulase-free xylanase from a novel thermo-haloalkaliphilicBacillus halodurans in producing xylooligosaccharides. Biotechnol Lett, 2011; 33: 2279-2285.

Laskowski RA, Macarthur MW, Moss DS, Thornton JM. PROCHECK: a program to check the stereochemical quality of protein structures. J ApplCrystallogr, 1993; 26: 283-291.

Lin $\mathrm{Q}, \mathrm{Ou} \mathrm{S}$, Wen $\mathrm{Q}$. In vitro antioxidant activity of feruloyl arabinose isolated from maize bran by acid hydrolysis. J Food SciTechnol, 2014; 51: 1356-1362.

Lowry OH, Rosebrough NJ, Farr AL, Randall RJ.Protein measurement with the Folin phenol reagent. J Biol Chem. 1951; 193: 265 275.

Mandelli F, Brenelli L, Almeida R, Goldbeck R, Wolf L, Hoffmam Z, Ruller R, Rocha G, Mercadante A, Squina F. Simultaneous production of xylooligosaccharides and antioxidant compounds from sugarcane bagasse via enzymatic hydrolysis. Ind Crops Prod, 2014; 52: $770-775$.

Mander P, Choi YH, Pradeep G, Choi YS, Hong JH, Cho SS, Yoo, JC. Biochemical characterization of xylanase produced from Streptomyces sp. CS624 using an agroresidue substrate. Process Biochem, 2014; 49: 451-456.

Mensor LL, Menezes FS, Leitão GG, Reis AS, Santos TCd, Coube CS, Leitão SG. Screening of Brazilian plant extracts for antioxidant activity by the use of DPPH free radical method. Phytother Res, 2001; 15: $127-130$

Moure A, Gullón P, Domínguez H, Parajó JC. Advances in the manufacture, purification and applications of xylo-oligosaccharides as food additives and nutraceuticals. Process Biochem, 2006; 41: 1913-1923.

Mussatto SI, Mancilha JM. Non-digestible oligosaccharides: a review. CarbohydrPolym, 2007; 68: 587-597.

Nelson N. A photometric adaptation of the Somogyi method for the determination of glucose. J Biol Chem. 1944; 153: 375-380.

Quettier-Deleu C, Gressier B, Vasseur J, Dine T, Brunet C, Luyckx M, Cazin M, Cazin J.-C, Bailleul F, Trotin F. Phenolic compounds and antioxidant activities of buckwheat (Fagopyrum esculentum Moench) hulls and flour. J Ethnopharmacol, 2000;72: 35-42.

Rashad MM, El-Torky AMM, Nooman MU, Keshta AT, Mahmoud HA, Mahmoud AE. Enhanced production of cellulase-free xylanase from Bacillus amyloliquifaciens NNRL B-14393 by solid state fermentation of water hyacinth and its application in degradation of agricultural residues. Asian J Microbiol Biotechnol Environ Sci, 2015a; $17: 865-877$. 
Rashad MM, Fathy SA, Abdou HM, Mahmoud AE, Jwanny EW. Production of $\beta$-xylanase from edible mushroom PleurotusOstreatus. Egypt J Biotechnol, 2002; 11: 394-408.

Rashad MM, Mahmoud AE, Nooman MU, El-Torky AMM, Keshta AT, Mahmoud HA. Purification and characterization of a new thermoalkali-stable xylanase produced from Bacillus amyloliquifaciens NRRL B-14393 by solid-state fermentation of water hyacinth. Res J Pharm BiolChemSci, 2015b; 6: 467-478.

Reddy SS, Krishnan C. Production of prebiotics and antioxidants as health food supplements from lignocellulosic materials using multi enzymatic hydrolysis. Int J ChemSci, 2010; 8: 535-549.

Rivas S, Conde E, Moure A, Domínguez H, Parajó, JC. Characterization, refining and antioxidant activity of saccharides derived from hemicelluloses of wood and rice husks. Food Chem, 2013; 141: 495 502 .

Sheu WHH, Lee IT, Chen W, Chan YC. Effects of xylooligosaccharides in type 2 Diabetes Mellitus. J NutrSciVitaminol, 2007; 54: 396-401.

Somogyi M. Notes on sugar determination. J BiolChem, 1952; 195: 19-23

Suganuma T, Matsuno R, Ohnishi M, Hiromi K. A study of the mechanism of action of Taka-amylase $\mathrm{A}$ on linear oligosaccharides by product analysis and computer simulation. J Biochem, 1978; 84: 293-316.

Swennen K, Courtin CM, Lindemans GCJE, Delcour JA. Large scale production and characterization of wheat bran arabinoxylooligosaccharides. J Sci Food Agric, 2006; 86: 1722-1731.

Thoma JA, Brothers C, Spradlin JE. Subsite mapping of enzymes. Studies on Bacillus subtilis amylase. Biochemistry, 1970; 9: 1768-1775.

Tison MC, André-Leroux G, Lafond M, Georis J, Juge N, Berrin J.-G. Molecular determinants of substrate and inhibitor specificities of the Penicilliumgriseofulvum family 11 xylanases. BBA Proteins Proteom, 2009; 1794: 438-445.
Toshio I, Noriyoshi I, Toshiyuki N, Kunimasa K. Production of xylobiose, Japanese Patent JP, $2119790,1990$.

Vazquez M, Alonso J, Domınguez $\mathrm{H}$, Parajó J. Xylooligosaccharides: manufacture and applications. Trends Food Sci Tech, 2000; 11: 387-393.

Veenashri B, Muralikrishna G. In vitro anti-oxidant activity of xylo-oligosaccharides derived from cereal and millet brans-A comparative study. Food Chem, 2011;126: 1475-1481.

Yang R, Xu S, Wang Z, Yang W. Aqueous extraction of corncob xylan and production of xylooligosaccharides. LWT -Food Sci Technol,2005; 38: 677-682.

Yang S, Yan Q, Jiang Z, Li L, Tian H, Wang Y. High-level of xylanase production by the thermophilic Paecilomycesthemophila J18 on wheat straw in solid-state fermentation. BioresourTechnol, 2006; 97: 1794-1800.

Yuan X, Wang J, Yao H. Antioxidant activity of feruloylated oligosaccharides from wheat bran. Food Chem, 2005; 90: 759-764.

Zhao LC, Wang Y, Lin JF, Guo LQ. Adsorption and kinetic behavior of recombinant multifunctional xylanase in hydrolysis of pineapple stem and bagasse and their hemicellulose for xylooligosaccharide production. Bioresour Technol, 2012; 110: 343-348.

\section{How to cite this article:}

Rashad MM, Mahmoud AE, Nooman MU, Mahmoud HA, ElTorky AEM, Keshta AT. Production of antioxidant xylooligosaccharides from lignocellulosic materials using Bacillus amyloliquifaciens NRRL B-14393 xylanase. J App Pharm Sci, 2016; 6 (06): 030-036. 